Editors' Note: In reference to Rudick and Miller's editorial, "Multiple sclerosis or multiple possibilities: The continuing problem of misdiagnosis," Dr. Deisenhammer calls attention to the importance of CSF oligoclonal band analysis in difficult diagnostic cases. The authors agree but point out reasons for caution. Drs. Kano et al. ask whether lesion location had an effect on brain or body temperature in the study by Whiteley et al., "Do acute phase markers explain body temperature and brain temperature after ischemic stroke?"

Megan Alcauskas, MD, and Robert C. Griggs, MD

\section{MULTIPLE SCLEROSIS OR MULTIPLE POSSIBILITIES: THE CONTINUING PROBLEM OF MISDIAGNOSIS}

Florian Deisenhammer, Innsbruck, Austria: Drs. Rudick and Miller discuss avoiding multiple sclerosis (MS) misdiagnosis, which occurs due to overuse and misinterpretation of MRI. ${ }^{1}$ I agree but would like to emphasize the importance of CSF oligoclonal bands (OCB) investigation. It is incomprehensible that a diagnostic test of roughly $95 \%$ sensitivity and $85 \%-90 \%$ specificity has been dropped in the latest version of MS diagnostic criteria., ${ }^{2,3}$ Physicians and patients would readily utilize a diagnostic test with this type of proven performance. MS experts increasingly face patients who are referred because of unspecific MRI white matter lesions and those with somatoform disorders misdiagnosed as MS. In this context, the negative predictive value of $90 \%$ of a negative OCB result should also be stressed. ${ }^{4}$ MS diagnostic criteria should include CSF investigation in the diagnosis of MS. There are also clear guidelines available on how to conduct CSF analyses. ${ }^{3}$

Author Response: Richard A. Rudick, Cleveland; Aaron Miller, New York: We agree with Dr. Deisenhammer that CSF analysis can be very helpful in difficult cases. Results can add to confidence in the diagnosis in patients thought not to have MS, and in atypical MS. However, we would caution against over-reliance on CSF test results, for several reasons:

1. The performance characteristics for CSF OCB have been studied more extensively in well-established MS than in patients with clinically or radiologically isolated syndromes. In our experience, CSF may be negative for OCB at initial presentation and positive at a later time point;

2. There are data demonstrating that OCB are nonspecific. Inflammatory and infectious diseases are commonly accompanied by OCB, and even infarcts or tumors may be accompanied by CSF OCB; and

3. Performance characteristics for OCB are technique dependent. As with other diagnostic tests, specificity declines as sensitivity increases. Similar to MRI, CSF test results should be interpreted for each individual case by a neurologist experienced in diagnosis and management of MS.

(C) 2013 American Academy of Neurology

1. Rudick RA, Miller AE. Multiple sclerosis or multiple possibilities: the continuing problem of misdiagnosis. Neurology 2012;78:1904-1906.

2. Polman $\mathrm{CH}$, Reingold SC, Banwell B, et al. Diagnostic criteria for multiple sclerosis: 2010 revisions to the McDonald criteria. Ann Neurol 2011;69:292-302.

3. Freedman MS, Thompson EJ, Deisenhammer F, et al. Recommended standard of cerebrospinal fluid analysis in the diagnosis of multiple sclerosis: a consensus statement. Arch Neurol 2005;62:865-870.

4. Bourahoui A, de Seze J, Guttierez R, et al. CSF isoelectrofocusing in a large cohort of MS and other neurological diseases. Eur J Neurol 2004;11:525-529.

\section{DO ACUTE PHASE MARKERS EXPLAIN BODY TEMPERATURE AND BRAIN TEMPERATURE AFTER ISCHEMIC STROKE?}

Osamu Kano, Ken Ikeda, Yasuo Iwasaki, Tokyo: Whiteley et al. ${ }^{1}$ reported that higher level of circulating markers of the acute inflammatory response in acute stroke were associated with higher temperatures in normal brain. They found no association between blood markers of inflammation and brain temperature in different regions of brain. The authors measured 3 markers of inflammation: C-reactive protein, interleukin-6, and fibrinogen. Higher temperature in diffusion-weighted imaging-abnormal brain was not associated with higher body temperature at the time of the first scan, but was associated with higher contemporaneous body temperature at the second scan. Was there any correlation between ischemic lesions and markers of inflammation? For example, did ischemic lesions in the infratentorial lesions correlate with 
one of these measurements? Body temperature is related to brain lesion in the hypothalamus and direct or indirect damage to the hypothalamus could contribute to the findings. In addition to brain cooling, elevating these biomarkers should be explored further.

Author Response: Joanna M. Wardlaw, William N. Whiteley, Ralph Thomas, Edinburgh; Gordon Lowe, Ann Rumley, Glasgow; Bartosz Karaszewski, Krakow; Paul Armitage, Ian Marshall, Katherine Lymer, Martin Dennis, Edinburgh: We thank Kano et al. for their comments. All the patients had supratentorial acute ischemic lesions. We did not examine the effect of lesion location on brain or body temperature because the study was not large enough to do this properly. We were interested in whether it was the acute diffusion imaging lesion temperature that was responsible for the rise in body temperature or whether other factors drive body temperature changes after stroke (i.e., general response to inflammation after stroke). Our results suggest the latter given that temperature in normal brain was more closely associated with body temperature early on and with plasma markers of inflammation. We suspect that elevated ischemic lesion temperature is controlled by a different set of factors from those that raise body temperature after stroke.

(C) 2013 American Academy of Neurology

1. Whiteley WN, Thomas R, Lowe G, et al. Do acute phase markers explain body temperature and brain temperature after ischemic stroke? Neurology 2012;79:152-158.

\section{Neurology ${ }^{\circledR}$ WriteClick: Join the Debate!}

The editors encourage comments about recent articles through WriteClick:

Go to www.neurology.org and click on the "WriteClick" tab at the top of the page. Responses will be posted within 72 hours of submission.

Before using WriteClick, remember the following:

- WriteClick is restricted to comments about studies published in Neurology within the last eight weeks

- Read previously posted comments; redundant comments will not be posted

- Your submission must be 200 words or less and have a maximum of five references; reference one must be the article on which you are commenting

- You can include a maximum of five authors (including yourself) 


\section{Neurology}

Do acute phase markers explain body temperature and brain temperature after ischemic stroke?

Osamu Kano, Joanna M. Wardlaw, Ken Ikeda, et al. Neurology 2013;80;777-778

DOI 10.1212/01.wnl.0000427487.25486.23

This information is current as of February 18, 2013

\section{Updated Information \&} Services

References

Errata

Permissions \& Licensing

Reprints including high resolution figures, can be found at: http://n.neurology.org/content/80/8/777.2.full

This article cites 1 articles, 1 of which you can access for free at: http://n.neurology.org/content/80/8/777.2.full\#ref-list-1

An erratum has been published regarding this article. Please see next page or:

/content/81/1/98.2.full.pdf

Information about reproducing this article in parts (figures,tables) or in its entirety can be found online at:

http://www.neurology.org/about/about_the_journal\#permissions

Information about ordering reprints can be found online:

http://n.neurology.org/subscribers/advertise

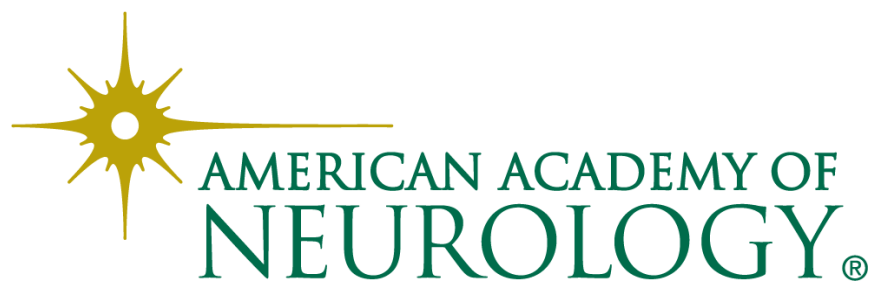


load of varicella-zoster virus (VZV) is higher in patients with MS at relapse phase than those in remission. The status of the disease course in all patients with MS should be determined before sampling.

Four out of the 15 patients with MS with relapse were on interferon (IFN)- $\beta$ treatment. It has been shown that the administration of IFN- $\beta$ can lead to the reduction of JCV genome ${ }^{3}$ and may result in a false-negative due to decreasing the JCV titer and T-cell response. Thus, patients taking IFN- $\beta$ should be excluded from this study.

In addition, we would not have included clinically isolated syndrome (CIS) in this study cohort. Approximately $80 \%$ of patients with CIS develop MS, while the rest do not. ${ }^{4}$ Patients with CIS should not be considered for evaluation of JCV-specific T-cell response under corticosteroid therapy.

Author Response: Renaud A. Du Pasquier, Mathieu Canales, Myriam Schluep, Lausanne, Switzerland: We thank Mr. Zahednasab for his interest in our article. As we explained in the Methods, we enrolled only patients with MS who had a relapse severe enough to warrant 3 days of IV corticosteroids followed by tapering oral prednisone. The mean delay between the onset of symptoms and steroid treatment was 11.6 days (range 0-54 days). Concerning VZV and MS, the paper of Sotelo et al. has been challenged. ${ }^{5}$ In addition, VZV is not JCV so it is difficult to draw any conclusions from this comparison.
Regarding IFN- $\beta$, as we mentioned: "If a patient exhibited no T-cell response against a given virus before and after CS, then this patient was not taken into account in our analyses for the given virus and the given assay." This was the case in 2 of 4 patients on IFN- $\beta$, who are not part of the JCV-specific cellular immune response part of our article and thus not included into the analysis of corticosteroids effects. Finally, in the patients with CIS, diseases other than MS were carefully ruled out. Currently, 4 of 8 of these patients with CIS have converted to definite MS, confirming that their inclusion was appropriate.

(C) 2013 American Academy of Neurology

1. Antoniol C, Jilek S, Schluep M, et al. Impairment of JCV-specific T-cell response by corticotherapy: effect on PML-IRIS management? Neurology 2012;79:2258-2264.

2. Sotelo J, Martinez-Palomo A, Ordonez G, et al. Varicella zoster virus in cerebrospinal fluid at relapses of multiple sclerosis. Ann Neurol 2008;63:303-311.

3. Delbue S, Guerini FR, Mancuso R, et al. JC virus viremia in interferon-beta-treated and untreated Italian multiple sclerosis patients and healthy controls. J Neurovirol 2007; 13:73-77.

4. Fisniku LK, Brex PA, Altmann DR, et al. Disability and T2 MRI lesions: a 20-year follow-up of patients with relapse onset of multiple sclerosis. Brain 2008;131:808-817.

5. Burgoon MP, Cohrs RJ, Bennett JL, et al. Varicella zoster virus is not a disease-relevant antigen in multiple sclerosis. Ann Neurol 2009;65:474-479.

\section{CORRECTIONS}

\section{Randomized controlled trial of trigeminal nerve stimulation for drug-resistant epilepsy}

In the article "Randomized controlled trial of trigeminal nerve stimulation for drug-resistant epilepsy" (Neurology ${ }^{\circledR}$ 2013;80:786-791) by DeGiorgio et al., two corrections are needed. The first is in the abstract, where the confidence interval should read "Subjects in the treatment group were more likely to respond than patients randomized to control (odds ratio 1.73, confidence interval 0.59-5.1)." The second correction is in the level of evidence statement. Although there was improvement within the active treatment group alone, there was no significant difference in effect between the treatment and control groups. The study was insufficiently powered to exclude an important difference. Therefore, the level of evidence statement should read "Because of a lack of statistical precision, this Class II study provides insufficient evidence to determine the efficacy of trigeminal nerve stimulation in patients with DRE." The editors regret the error and the misstatement.

WriteClick: Do acute phase markers explain body temperature and brain temperature after ischemic stroke?

In the WriteClick Author Response "Do acute phase markers explain body temperature and brain temperature after ischemic stroke?" by J.M. Wardlaw et al. (Neurology $\left.{ }^{\circledR} 2013 ; 80: 778\right)$, there is an error in one of the author affiliations. It should read Bartosz Karaszewski, Gdansk. The authors regret the error. 